\title{
Determinan MP-ASI Pada Bayi Usia Kurang Dari 6 Bulan
}

\author{
Syastriani Isna Putri Syarif ${ }^{1}$, Anita ${ }^{2}$ \\ Politeknik baubau, Baubau, Diploma Tiga Kebidanan, Jurusan Kesehatan Sulawesi Tenggara, Indonesia ${ }^{1,2}$

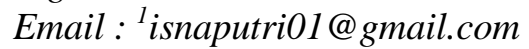

\begin{abstract}
Complementary foods ASI is nutritious food or drink that is given to babies aged 6-24 months to fulfill nutrition for the baby. Complementary feeding at inappropriate times can have a negative effect on babies, such as allergies, diarrhea, disorders of the digestive tract and so on. The purpose of this study was to determine the factors causing complementary feeding to infants less than 6 months old in the Sorawolio Public Health Center, Baubau City. The method in this research is to use a descriptive survey method. Withdrawal of samples using a total sample technique with a total sample of 16 respondents. The results showed that $62.5 \%$ of mothers who gave complementary breastfeeding $<6$ months had poor knowledge about the pattern and timing of complementary feeding, while 37.5\% of mothers had good knowledge about the timing of complementary feeding, and The negative attitude shown by the mother during complementary feeding shows $68.8 \%$ and a positive attitude
\end{abstract}

Keywords : MP-ASI, Infants Less Than 6 Months, Time of giving MP-ASI

\begin{abstract}
ABSTRAK
Makanan pendamping ASI merupakan makanan atau minuman bernutrisi yang diberikan pada bayi berusia 624 bulan sebagai pemenuhan nutrisi bagi sang bayi. Pemberian makanan pendamping ASI diwaktu yang tidak tepat dapat memberikan efek yang buruk pada bayi, misalnya seperti alergi,, diare, gangguan pada saluran pencernaan dan sebagainya. Tujuan Penelitian ini adalah untuk mengetahui factor penyebab pemberian MP-ASI pada bayi kurang dari 6 Bulan di Wilayah Kerja Puskesmas Sorawolio Kota Baubau. Metode dalam penelitian ini yaitu menggunakan metode survei deskriptif. Penarikan sampel menggunakan Teknik total sampel dengan jumlah sampel sebanyak 16 responden. Hasil penelitian menunjukkan ibu yang memberikan MP-ASI <6 bulan sebesar 62,5\% memiliki pengetahuan yang kurang baik tetang pola dan waktu pemberian MP-ASI, sedangkan sebesar 37,5\% ibu memiliki pengetahuan yang baik tantang waktu pemberian MP-ASI, serta sikap negative yang ditunjukkan ibu dalam waktu pemberian MP-ASI menunjukkan sebesar $68,8 \%$ dan sikap positif
\end{abstract}

Kata Kunci: MP-ASI, Bayi Kurang dari 6 Bulan, Waktu Pemberian MP-ASI 


\section{PENDAHULUAN}

Air Susu Ibu (ASI) merupakan makanan pertama bayi yang memiliki peranan penting dalam tumbuh kembang, karena terbukti memiliki manfaat sangat besar untuk jangka panjang[1]. WHO telah merekomendasikan bahwa bayi harus secara ekslusif mendapat ASI pada usia 6 bulan pertama, dengan pengenalan makanan pendamping ASI (MP-ASI) yang sesuai umur dan terus memberikan ASI selama 2 tahun [2]. Pemberian makan pendamping ASI (MP-ASI) yang tidak tepat waktu dapat mengakibatkan halhal yang merugikan, apabila terlalu dini (kurang dari 6 bulan) dapat menimbulkan resiko diare, dehidrasi, produksi ASI menurun dan alergi, sedangkan pemberian makanan pendamping ASI (MP-ASI) yang terlambat (sesudah usia 7 bulan) dapat berpotensi untuk terjadinya gagal tumbuh, defisiensi zat besi serta gangguan tumbuh kembang [3].

Usia 6 bulan sampai dengan 24 bulan merupakan masa rawan pertumbuhan bayi/anak. Tumbuh kembang anak akan tergangu jika makan pendamping tidak diperkenalkan pada usia 6 bulan, atau pemberianya dengan cara yang tidak tepat. Karena diusia 6 bulan, kebutuhan bayi untuk energi dan nutrisi mulai melebihi apa yang terkandung dalam ASI, dan makanan pendamping diperlukan untuk memenuhi kebutuhan tersebut [4].Pada usia ini perkembangan bayi sudah cukup siap untuk menerima makanan lain. Peraturan Pemerintah No 33 tahun 2012, memberikan makan pendamping ASI (MP-ASI) yang tepat sejak umur 6 bulan dan meneruskan pemberian ASI sampai umur 2 tahun. Pemberian MP-ASI yang terlalu dini merupakan salah satu faktor penghambat pemberian ASI Ekslusif.

Hasil penelitian sebelumnya oleh Asriati di Rumah Bersalin Mattiro Baji Gowa Sulawesi Selatan pada tahun 2013, gambaran pengetahuan ibu tentang waktu pemberian MP-ASI yang tepat masih sangat kurang yaitu hanya 23,4\% dalam kategori baik [5]. Padahal, hal ini sangat penting untuk diketahui oleh seorang ibu karena menyangkut sistem pencernaan bayi, sistem pencernaan bayi yang matang pada usia sekitar 6 bulan. Dan pada kenyataanya, praktek pemberian MP-ASI dini sebelum usia 6 bulan masih banyak di lakukan di negara berkembang seperti indonesia. Hal ini akan berdampak terhadap kejadian infeksi tinggi, seperti diare, infeksi saluran napas, alergi, hingga gangguan pertumbuhan [6,7].
Salah satu faktor yang mempengaruhi rendahnya pemberian ASI ekslusif adalah praktek pemberian makanan pendamping ASI (MP-ASI) pada bayi usia kurang dari 6 bulan, termaksuk didalamnya praktek pemberian makanan prelakteal. Penelitian yang dilakukan oleh Fikawati dan Syafiq (2013) menemukan kegagalan pelaksanaan ASI Ekslusif telah dimulai sejak 3 hari pertama kelahiran yaitu, lebih dari $80 \%$ responden yang tidak ASI ekslusif 4 bulan telah memberikan makanan/minuman prelakteal dalam 3 hari pertama kepada bayinya [8]. Penelitian yang dilakukan oleh Kumalasari (2015) tentang faktor-faktor yang berhubungan dengan pemberian makanan pendamping ASI dini di Wilayah Binaan Puskesmas Sidomulyo Pekan Baru didapatkan hasil bahwa ibu yang memiliki tingkat pengetahuan dalam kategori "tidak baik" memilki resiko besar 2,425 kali untuk memberikan MP-ASI dini pada bayi usia $<6$ [9].

Menurut WHO (2011), hanya 40\% bayi di dunia yang mendapat ASI ekslusif sedangkan $60 \%$ bayi lainnya ternyata telah mendapatkan Makanan Pendamping Air Susu Ibu (MP-ASI) saat usia kurang dari 6 bulan. Hal ini tersebut menggambarkan bahwa pemberian ASI ekslusif masih rendah sedangkan praktek pemberian MPASI dini diberbagai negara masih tinggi. Jumlah pemberian MP-ASI dini dan ASI ekslusif tidak hanya terjadi di negara-negara maju, tetapi juga terjadi di negara berkembang seperti di Indonesia $[2,10]$. Cakupan pemberian ASI eklusif pada bayi 0-6 bulan di Indonesia pada tahun 2014 sebesar $53,3 \%$. Jika dibandingkan pada tahun 2013, cakupan pemberian ASI ekslusif mengalami penurunan sebesar 2,04\% dari angka 54,34\%. Sementara itu dalam sumber yang sama juga dinyatakan bahwa di Sulawasi Selatan, cakupan pemberian ASI ekslusif pada tahun 2014 sebesar $69,3 \%$, mengalami peningkatan jika dibandingkan pada tahun 2013 yang hanya sebesar 56,2\% [11].

Pemberian MP-ASI dini ( $<6$ bulan) di Indonesia menurut Survei Kesehatan Dasar Indonesia (SDKI) 2012, bayi yang mendapat makanan pendamping ASI usia 0-1 bulan sebesar 96\%, pada usia 2-3 bulan sebesar $16,7 \%$, dan usia $4-5$ bulan sebesar $43,9 \%$. Sedangkan, pemberian makanan pendamping ASI terlambat ( $<6$ bulan) di Indonesia terjadi hanya sebagian kecil ibu yang memberikan makanan pendamping ASI pada bayi di atas usia 6 bulan. Berdasarkan data profil kesehatan Sulawesi Tenggara Kabupaten Muna Barat pada tahun 2015 terdapat 1.045 bayi namun 
yang mendapat ASI ekslusif hanya sebanyak 300 bayi atau sebesar $28,71 \%$. Sedangkan tahun 2016 terdapat 5.652 bayi yang mendapat ASI ekslusif sebanyak 240 bayi saja atau sebesar 4,25\%. Kabupaten Muna Barat merupakan Kabupaten Kota yang memiliki cakupan pemberian ASI Ekslusif yang paling rendah sebanyak 2 tahun terakhir yaitu tahun 2015 dan tahun 2016 kemudian disusul oleh Kabupaten Buton Selatan (30,68\%) dan Kabupaten Muna (32,33\%) tahun 2015. Sedangkan tahun 2016 disusul oleh kota Baubau (36,98\%) dan Konawe Kepulauan $(39,12 \%)$. Berdasarkan data yang diperoleh dari Wilayah Kerja Puskesmas Sorawolio pada tahun 2017 dari bulan Januari sampai bulan Agustus ibu yang memberikan ASI ekslusif pada bayinya hanya sebesar (30\%), sedangkan target sasaran dari Dinas Kesehatan untuk pemberian ASI ekslusif sebesar (54\%), dan dari data buku laporan gizi yang didapat untuk pemberian ASI ekslusif di Puskesmas Sorawolio masih sangat kurang dari target yang diberikan. Berdasarkan Uraian Latar Belakang, peneliti tertarik untuk melakukan penelitian tentang: Determinan Pemberian MP-ASI Pada Bayi Usia Kurang dari 6 Bulan di Wilayah Kerja Puskesmas Sorawolio Kota Baubau Tahun 2018 [12]. Tujuan penelitian ini yaitu untuk mengetahui Penyebab Pemberian MP-ASI Pada Bayi Usia 1-5 bulan di wilayah Kerja Puskesmas Sorawolio Kota Baubau Tahun 2018.

\section{METODE PENELITIAN}

Berdasarkan tujuan penelitian maka jenis penelitain yang digunakan adalah penelitian Kuantitatif dengan menggunakan pendekatan deskriptif survey analitik yaitu untuk mengetahui penyebab pemberian MP-ASI dini pada bayi usia 6 bulan di Wilayah Kerja Puskesmas Sorawolio kota Baubau Tahun 2018.

Populasi pada penelitian ini adalah keseluruhan ibu yang mempunyai anak usia 1-6 bulan di Wilayah Kerja Puskesmas Sorawoliio kota Baubau Tahun 2018 yakni sebanyak 16 ibu. Sampel dalam penelitian ini berjumlah $16 \mathrm{ibu}$, dengan teknik pengambilann sampel berupa Total Sampling, yaitu keseluruhan populasi dijadikan sampel penelitian

Metode Analisis yang digunakn yaitu analisis Univariat yakni proses menganalisis tiap-tiap variabel yang ada secara deskriptif dengan menghitung distribusi frekuensi dan presentasedari setiap variabel [13].

\section{HASIL DAN PEMBAHASAN}

Hasil analisa univariat dalam penelitian ini untuk membuat gambaran pemberian MP-ASI pada bayi usia 1-6 bulan di Wilayah Kerja Puskesmas Sorawolio Kota Baubau Tahun 2018.

\section{Tabel 1}

Distribusi Frekuensi Respondent Berdasarkan Kelompok Umur Ibu Wilayah Kerja Peskesmas Sorawolio Kota Baubau Tahun 2018

\begin{tabular}{|c|c|c|}
\hline Umur & Jumlah (f) & Persentase (\%) \\
\hline $21-25$ & & \\
\hline Tahun & 7 & $43,8 \%$ \\
\hline Tahun & 4 & $25,0 \%$ \\
\hline $\begin{array}{c}\text { Tahun } \\
>35\end{array}$ & 2 & $12,5 \%$ \\
\hline Tahun & $\underline{3}$ & $18,8 \%$ \\
\hline Total & 16 & $100 \%$ \\
\hline
\end{tabular}

Sumber : data primer peneliti 2018

Berdasarkan Tabel 1 diatas menunjukan bahwa dari 16 responden sebagian besar berumur 21-25 tahun yaitu sebanyak $7(43,8 \%)$ responden, sedangkan yang berumur 26-30 tahun sebanyak 4 $(25,0 \%)$ responden, yang berumur 31-35 sebanyak $2(12,5 \%)$ responden dan yang berumur $>35$ tahun berjumlah $3(18,8 \%)$ responden.

\section{Tabel 2}

Distribusi Frekuensi Responden Berdasarkan Kategori Pendidikan di Wilayah Kerja Puskesmas Sorawolio Kota Baubau Tahun 2018.

\begin{tabular}{ccc}
\hline Pendidikan & Jumlah (f) & $\begin{array}{c}\text { Persentase ( } \\
\mathbf{\%})\end{array}$ \\
\cline { 3 - 3 } SD & 2 & $12,5 \%$ \\
SMP & 3 & $18,8 \%$ \\
SMA & 7 & $43,8 \%$ \\
SI & 4 & $25,0 \%$ \\
Total & $\mathbf{1 6}$ & $\mathbf{1 0 0 \%}$ \\
\hline
\end{tabular}

Sumber : data primer peneliti 2018

Berdasarkan Tabel 2 menunjukan bahwa dari 16 responden sebanyak $2(12,5 \%)$ responden berpendidikan $\mathrm{SD}, 3(18,8 \%)$ responden berpendidikan SMP, $7 \quad(43,8 \%)$ esponden berpendidikan SMA, dan $4(25,0 \%)$ responden berpendidikan $\mathrm{S} 1$.

\section{Tabel 3}

Distribusi Frekuensi Responden Berdasarkan Kategori Pekerjaan di Wilayah Kerja Puskesmas Sorawolio Kota Baubau Tahun 2018. 


\begin{tabular}{ccc}
\hline Pekerjaan & $\begin{array}{c}\text { Jumlah } \\
(\mathbf{f})\end{array}$ & $\begin{array}{c}\text { Presentase } \\
(\mathbf{\%})\end{array}$ \\
\hline IRT & 9 & $56,2 \%$ \\
PNS & 2 & $12,5 \%$ \\
Wiraswasta & 5 & $31,12 \%$ \\
Total & $\mathbf{1 6}$ & $\mathbf{1 0 0 \%}$ \\
\hline
\end{tabular}

Sumber: data primer peneliti 2018

Berdasarkan Tabel 3 menunjukan bahwa dari 16 responden sebanyak $9(56,2)$ responden memiliki pekerjaan sebagai IRT, $2(12,5)$ responden memiliki pekerjaan sebagai PNS, dan $5(31,2 \%)$ responden memiliki pekerjaan sebagai wiraswasta.

\section{Tabel 4}

Distribusi Frekuensi Responden Berdasarkan Kategori Usia Bayi di Wilayah Kerja Puskesmas Sorawolio Kota Baubau Tahun 2018.

\begin{tabular}{ccc}
\hline Usia Bayi & $\begin{array}{c}\text { Jumlah } \\
(\mathbf{f})\end{array}$ & $\begin{array}{c}\text { Presentase } \\
(\boldsymbol{\%})\end{array}$ \\
\cline { 2 - 2 } 1 Bulan & 0 & $0 \%$ \\
2 Bulan & 4 & $25,0 \%$ \\
3 Bulan & 7 & $43,8 \%$ \\
4 Bulan & 3 & $18,8 \%$ \\
5 Bulan & 2 & $12,5 \%$ \\
Total & $\mathbf{1 6}$ & $\mathbf{1 0 0 \%}$ \\
Sumber : data primer penetiti 2018
\end{tabular}

Berdasarkan Tabel4 menunjukan bahwa dari 16 responden tidak ada ibu yang memiliki bayi usia 1 bulan, sementara terdapat $4(25,0 \%)$ ibu yang memiliki bayi usia 2 bulan, $7(43,8 \%)$ ibu yang memiliki bayi usia 3 bulan, $3(18,8 \%)$ ibu yang memiliki bayi usia 4 bulan dan $2(12,5 \%)$ ibu yang memiliki bayi usia 5 bulan.

\section{Tabel 5}

Distribusi Frekuensi Jawaban Responden Tentang Jumlah bayi yang diberikan MP-ASI Usia 1-6 Bulan di Wilayah Kerja Puskesmas Suorawolio Kota Baubau Tahun 2018.

\begin{tabular}{ccc}
\hline $\begin{array}{c}\text { Pemberian } \\
\text { MP-ASI }\end{array}$ & Jumlah & $\begin{array}{c}\text { Preaentase } \\
(\%)\end{array}$ \\
\hline Memberikan & 10 & $62,5 \%$ \\
Tidak & 6 & $37,5 \%$ \\
$\begin{array}{c}\text { Memberikan } \\
\text { Jumlah }\end{array}$ & 16 & $100 \%$ \\
\hline
\end{tabular}

Sumber: data primer peneliti 2018

Berdasarkan Tabel 5 menunjukan bahwa dari 16 responden yang memberikan MP-ASI sebanyak $10(62,5 \%)$ responden dan yang tidak memberikan MP-ASI sebanyak 6 (37,5\%) responden.
Tabel 6

Distribusi Frekuensi Jawaban Responden Tentang Pengetahuan terhadap pemberian MPASI pada bayi Usia 1-5 Bulan di Wilayah Kerja Puskesmas Sorawolio Kota Baubau Tahun 2018.

\begin{tabular}{ccc}
\hline Pengetahuan & $\begin{array}{c}\text { Jumlah } \\
(\mathbf{f})\end{array}$ & Presentase(\%) \\
\cline { 2 - 2 } Baik & 6 & $37,5 \%$ \\
Kurang & 10 & $62,5 \%$ \\
Total & $\mathbf{1 6}$ & $\mathbf{1 0 0 \%}$ \\
\hline
\end{tabular}

Sumber : data primer penelit 2018

Berdasarkaan Tabel 6 menunjukkan bahwa dari 16 responden yang berpengetahuan baik sebanyak 6 (37,5\%) responden dan berpengetahuan kurang sebanyak 10 orang $(62,5 \%)$.

Tabel 7

Distribusi Frekuensi Jawaban Responden Tentang Sikap Terhadap Pemberian MP-ASI pada Bayi Usia 1-5 Bulan di Wilayah Kerja Puskesmas Sorawolio Kota Baubau Tahun 2018.

\begin{tabular}{ccc}
\hline Sikap & $\begin{array}{c}\text { Jumlah } \\
(\mathbf{f})\end{array}$ & $\begin{array}{c}\text { Presentase } \\
(\boldsymbol{\%})\end{array}$ \\
\hline Baik & 5 & $31,2 \%$ \\
Kurang & 11 & $68,8 \%$
\end{tabular}

$\begin{array}{lll}\text { Total } & 16 & 100 \%\end{array}$

Sumber : data primer peneliti 2018 Berdasarkaan Tabel 7 menunjukkan bahwa dari

16 responden yang memiliki sikap positif sebanyak $5(31,2 \%)$ responden dan yang memiliki sikap negatif sebanyak $11(68,8 \%)$ responden.

Berdasarkan Tabel 6 bahwa pengetahuan responden yang terdapat dalam kuesioner penelitian yang memuat pernyataan tentang pengetahuan MP-ASI pada ibu. Hasil penelitian menunjukkan bahwa dari 16 responden yang memiliki pengetahuan dengan kategori baik berjumlah 6 orang responden sedangkan kategori kurang baik berjumlah 10 orang responden. Hal ini menunjukkan bahwa pengetahuan ibu di wilayah kerja Puskesmas Sorawolio tentang MPASI dikategorikan kurang baik hal inilah yang menyebabkan masih banyak ibu di wilayah kerja Puskesmas Sorawolio yang memberikan MP-ASI pada bayinya sebelum waktunya. Hasil penelitian yang dilakukan menunjukkan bahwa pengetahuan merupakan salah satu faktor penting bagi ibu untuk mengetahui usia bayi yang tepat untuk diberikan MP-ASI. Hasil penelitian ini sejalan dengan penelitian yang dilakukan oleh 
Siti awarni, Tahun 2013 yang menyatakan bahwa tingkat pengetahuan ibu sangat berpengaruh terhadap pemberian MP-ASI pada bayi [14]. Hal ini disebabkan pengetahuan merupakan landasan seseorang dalam mengambil keputusan, ibu yang memiliki pengetahuan baik cenderung akan lebih mengetahui usia yang tepat untuk memberikan MP-ASI pada bayinya sehingga iya tidak akan salah dalam bertindak, namun ibu yang memiliki pengetahuan kurang cenderung tidak memahami kapan waktu yang tepat untuk memberikan MPASI pada bayinya, sehingga sang ibu akan salah dalam waktu pemberian MP-ASI pada bayinya [15].

Berdasarkan Tabel 7 bahwa Sikap yang dimaksud adalah tanggapan responden untuk berfikir atau reaksi responden tentang pemberian MP-ASI pada bayinya. Hasil penelitian ini menunjukan bahwa dari 16 responden sebagian besar responden dengan sikap kurang sebanyak 11 $(68,8 \%)$ responden dimana sikap ibu dikatan kurang bila skor responden $\leq 50 \%$ dan sikap baik sebanyak $5(31,2 \%)$ responden dimana sikap ibu dikatakan baik jika skor jawaban $\geq 50 \%$. Hasil penelitian yang dilakukan menujukan bahwa sikap merupakan salah satu faktor penting bagi ibu untuk menentukan usia bayi yang tepat untuk diberikan MP-ASI. Pemahaman ibu yang kurang tepat tentang pemberian MP-ASI pada bayi akan mengarahkan ibu memiliki sikap yang memberikan tujuan ke arah negatif berupa pemberian MP-ASI pada bayi sebelum waktunya [16].

Hasil penelitian ini sejalan dengan penelitian yang dilakukan oleh Lina, dkk, tahun 2014 yang menyatakan bahwa ada hubungan yang bermakna antara sikap dan pemberian MP-ASI yakni Sikap yang positif akan mendorong ibu untuk berperilaku baik pula dengan memberikan MPASI pada usia yang tepat pada bayinya, namun sikap yang negatif akan membuat ibu berperilaku tidak baik pula dengan MP-ASI sebelum waktunya pada bayinya [15]. Hasil penelitian yang dilakukan menunjukkan bahwa sikap merupakan salah satu faktor penting bagi ibu untuk menentukan usia bayi yang tepat untuk diberikan MP-ASI [17,18].

\section{SIMPULAN}

Penelitian ini tentang Determinan Pembrian MPASI Pada Bayi Usia kurang dari 6 Bulan di Wilayah Kerja Puskesmas Sorawolio Kota Baubau Tahun 2018. Pada 16 orang sebagai Informan. Setelah diolah dan dibahas dapat ditarik kesimpiulan sebagai berikut: Responden dengan pengetahuan baik sebesar 6 responden
$(37,5 \%)$ dan pengetahuankurang baik sebesar 10 respondnen $(62,5 \%)$. Responden dengan sikap positif sebesar 5 responden $(31,2 \%)$ dan sikap negatif sebesar 11 responden $(68,8 \%)$

Rekomendasi bagi Ibu Di harapkan dengan adanya penelitian ini, para ibu mampu memahami tentang pemberian makanan pendamping ASI bagi bayi khususnya waktu yang tepat untuk memberikan makanan pendamping ASI serta mencari informasi tentang resiko jika memberikan makanan pendamping ASI terlalu dini bagi kesehatan bayi sehingga ibu dapat menghentikan kebiasaan buruk memberikan MPASI terlalu dini pada bayi. Bagi Petugas Kesehatan Di harapkan petugas kesehatan dapat lebih mengembangkan program- program kerja Puskesmas yang dapat menghilangkan kebiasaan pemberian makanan pendamping ASI yang terlalu dini di masyarakat melaluipenyuluhan yang dapat memberikan informasi baru bagi masyarakat sehingga pengetahuan masyarakat pun dapat meningkat.

Bagi Peneliti Selanjutnya Di harapkan bagi peneliti selanjutnya dapat mengembangkan lagi lebih lanjut mengenai topik ini, bahkan jika perlu membuat penelitian intervensi terhadap dampak pemberian makanan pendamping ASI terlalu dini.

\section{DAFTAR PUSTAKA}

[1] Kartini, Apoina, 2014, Jenis MP-ASI, Frekuensi dan Waktu Pertama Kali Pemberian MP-ASI sebagai Faktor Resiko Kejadian Gizi Lebih pada Bayi Usia 6-12 Bulan Di Kota Magelang

[2] World Health Organization (WHO), 2011. Complementary feeding :Family Foods for Breastfed Children. France :FSG MediMedia Ltd.pp:1-23

[3] World Health Organization(WHO) 2016. Exclusif Breastfeeding. [online]. Tersedia: http://www.who.int/nutrion/topics/exclusiv e_breastfeeding/en/. [4 april 2018]

[4] Maryunani A., 2012, Inisiasi Menyusui Dini ASI Ekslusif Dan Menajemen Laktasi, Jakarta: PT. Rineka Cipta.

[5] Asriati, 2013, Gambaran Pengetahuan Ibu tentang Pemberian Makanan Pendamping ASI di RB Mattiro Baji Kecamatan Sumba Opu Kabupaten Gowa Tahun 2013. FIK UIN Makassar

[6] Mutmainnah, 2011, Faktor-faktor yang Berhubungan dengan pengetahuan Ibu dalam Memberikan Makanan Pendamping Air Susu Ibu. 
[7] Chairani, K., 2013, Alasan ibu Memberikan Makanan Pendamping ASI (MP-ASI) dini dengan pendekatan teori Health Belief Model di wilayah kerja Puskesmas Kecamatan

[8] Fikawati, Sandra, Ahmad, S., 2013, Hubungan Antara Menyusui Segera (Immediate Breastfeeding) dan Pemberian ASI Ekslusif Sampai Empat Bulan, Jurnal Kedokteran Trisakti Vol.22 No.2

[9] Kumalasari, 2015, Faktor-faktor yang Berhubungan degan Pemberian Makanan Pendamping ASI Dini, Jakarta : EGC

[10] Krisnatuti. 2010. Gambaran Perilaku pola pemberian makanan pendamping ASI (MPASI) pada bayi 6-12 bulan, Jakarta : Nuha Medika

[11] Kementrian kesehatan Republik Indonesia, 2015, Pusat Data dan Informasi Situasi Gizi, Jakarta selatan : flashbooks.

[12] Profil Puskesmas Sulaa, Tahun 2018, Laporan cakupan ASI dan MP-ASI Puskesmas Sulaa, Baubau Tahun 2018
[13] Notoatmojo, Soekidjo. 2012. Metodologi Penelitian Kesehatan, Jakarta : Rineka Cipta.

[14] Muchtadi, D., 2013, Gizi untuk bayi, ASI, Susu formula dan Makanan Tambahan,Jakarta : Pustaka Sinar harapan

[15] Roesli, U., 2010. Inisiasi Menyusu Dini Plus ASI Ekslusif. Jakarta : Prestasi Bunda.

[16] Ginting, D., Sekarwana, Nanan, Sukandar, Hadyana, 2012, Pengaruh Karakteristik, Faktor Internal dan Eksternal Ibu Terhadap Pemberian MP-ASI Dini Pada Bayi Usia <6 Bulan Di Wilayah Kerja puskesmas barus jahe Kabupaten karo Provinsi

[17] Fitriana, 2013, Dampak Usia Pertama Makanan Pendamping ASI Terhadap Status Gizi bayi Usia 8-12 Bulan di Kecamatan seberang Ulu I Palembang Sari Pediatri.

[18] Kalanda, 2012, ASI dan Susu Formula Kandungan dan Manfaat ASI dan Susu Formula, Nuha Medika, Yogyakarta 